\title{
PROFIL PALATOSKISIS DI BAGIAN ILMU BEDAH PLASTIK BLU RSUP PROF. DR. R.D. KANDOU MANADO PERIODE JANUARI-DESEMBER 2011
}

\author{
${ }^{1}$ Kalsum Taufiq \\ ${ }^{2}$ Jan T. Ngantung \\ ${ }^{2}$ Maximillian C. H. Oley \\ ${ }^{1}$ Kandidat skripsi Fakultas Kedokteran Universitas Sam Ratulangi Manado \\ 2Bagian Bedah Fakultas Kedokteran Universitas Sam Ratulangi Manado \\ Email: kalsumtaufiq@yahoo.com
}

\begin{abstract}
After labioschizis, palatoschizis is the most frequently encountered congenital disorder with multifactorial causes, and is a disorder that can be found in every nation in the world. Among the factors, the genetic factor was agreed upon to be a major factor. This was a descriptive retrospective study. This study aimed to find out palatoschizis cases in the Division of Plastic Surgery, Prof. Dr. R.D. Kandou Hospital, Manado, from January to December 2011. The results showed that there were 40 cases of both disordersd in the Division of Plastic Surgery Prof Dr. R.D. Kandou Manado Hospital from January 2011 through December 2011, showing 55\% with palatoschizis and $45 \%$ with labiopalatoschizis. From the total cases, $53 \%$ were females in contrast to $47 \%$ males. Fifty-seven percent represented the most frequently treated age group of 1-4 years with $72.5 \%$ requiring palatoplasty. From the total number of palatoschizis cases, as many as $58 \%$ were caused by environmental factors. Fifty-two percent were unilateral palatoschizis, in comparison to 2.5\% bilateral. Conclusion: In the Division of Plastic Surgery, Prof. Dr. R.D. Kandou Hospital, Manado, from January to December 2011 most of the palatoschizis and labiopalatoschizis cases were unilateral. Environmental factors were the mot common etiology for most of the women who suffered from this disease. Palatoplasty procedures were most widely used among the largest age group of 1-4 years.
\end{abstract}

Keywords: palatoschizis, labiopalatoschizis.

Abstrak: Palatoskisis merupakan kelainan kongenital yang paling sering dijumpai setelah labioskisis dengan penyebab multifaktorial, dan dijumpai pada setiap bangsa di dunia. Diantara faktor-faktor penyebabnya, faktor genetika disepakati menjadi faktor utama. Palatoskisis lebih banyak ditemukan pada perempuan. Palatoskisis unilateral kiri lebih sering dari pada yang kanan. Penelitian ini bersifat retrospektif deskriptif untuk mengetahui tentang kejadian palatoskisis di Bagian Ilmu Bedah Plastik RSUP Prof. Dr. R.D. Kandou Manado periode Januari-Desember 2011. Hasil penelitian memperlihatkan jumlah kasus di Bagian Bedah Plastik RSUP Prof. Dr. R.D. Kandou Manado periode Januari-Desember 2011 sebanyak 40 kasus dengan palatoskisis (55\%) dan labiopalatoskisis (45\%), lebih sering pada perempuan (53\%) dibandingkan laki-laki (47\%). Kelompok usia yang tersering ditangani 1-4 tahun (57\%) dan jenis operasi yang digunakan yaitu palatoplasty $(72,5 \%)$. Faktor penyebab yang tersering ialah faktor lingkungan (58\%). Kasus palatoskisis unilateral sebanyak 52,5\% sedangkan yang bilateral 2,5\%. Simpulan: Di Bagian Ilmu Bedah Plastik RSUP Prof. Dr. R.D. Kandou Manado periode Januari-Desember 2011 sebagian besar kasus palatoskisis dan labiopalatoskisis ditemukan unilateral dengan lokasi defek terbanyak di bagian kiri. Jenis kelamin perempuan lebih sering ditemukan dan etiologi tersering yaitu faktor lingkungan. Kelompok usia yang tersering ditangani yaitu 1-4 tahun dan tindakan yang tersering digunakan ialah palatoplasty.

Kata kunci: palatoskisis, labiopalatoskisis. 
Labioskisis dan palatoskisis merupakan kelainan kongenital kraniofasial yang paling umum ditemukan, yaitu sekitar 1 dalam 700 kelahiran hidup. Labioskisis dan palatoskisis terjadi dalam spektrum keparahan anatomi dan sering ditemukan bersamaan dengan kelainan sistem organ lainnya. Keduanya dapat terjadi secara terpisah. Diperkirakan $46 \%$ dari individu yang terkena memiliki kedua labioskisis dan palatoskisis, sedangkan secara terpisah labioskisis ditemukan sekitar $21 \%$ dan palatoskisis $33 \%$. Penanganan kedua hal ini memiliki seni tertentu karena menyangkut fungsi, estetis, dan psikis dari penderita. Oleh karena itu, kelainan bawaan ini sebaiknya ditangani oleh tim ahli yang tidak hanya terdiri dari dokter ahli bedah plastik saja, tetapi juga harus melibatkan dokter ahli anak, ahli ortodonsi, ahli THT$\mathrm{KL}$, ahli anastesi, ahli jiwa, ahli rehabilitasi (speech therapist), ahli keperawatan, dan pekerja sosial. $^{1}$

Akhir-akhir ini masalah outcome dari tindakan palatoplasty yang menyangkut waktu operasi dan teknik operasinya sudah sangat menonjol dalam setiap pembicaraan para pakar palatoskisis dunia, karena dikatakan bahwa tindakan kompromi antara masa pertumbuhan dan proses bicara merupakan inti permasalahan. 2,3

\section{Definisi}

Palatoskisis ialah suatu saluran abnormal yang melewati langit-langit mulut dan menuju ke saluran udara di hidung. Pembentukan langit-langit mulut dimulai pada akhir minggu ke-5 gestasi. Pada tahap ini, langit-langit mulut terdiri dari dua bagian, yaitu bagian anterior (primer) dan posterior (sekunder). Prominens hidung medial membentuk segmen intermaksilaris (premaksilaris) yang terdiri dari langitlangit primer dan gigi seri. Langit-langit sekunder meluas ke foramen. ${ }^{2}$

\section{Anatomi}

Palatum atau langit-langit dari mulut yaitu sekat yang memisahkan rongga hidung dan rongga mulut. Berdasarkan embriologi, palatum terbagi dua, yaitu palatum primer dan palatum sekunder. Palatum primer meliputi bibir, alveolus, dan palatum durum (hard palate) yang terletak pada bagian anterior dari foramen insisiva. Palatum sekunder dimulai dari foramen insisiva kemudian meluas ke belakang meliputi palatum durum dan palatum mole (soft palate). Palatoskisis terdapat pada palatum sekunder sedangkan labioskisis pada palatum primer. Palatum durum dan palatum mole bersama-sama membentuk atap rongga mulut dan lantai rongga hidung. ${ }^{4}$

\section{Etiologi}

Etiologi palatoskisis bersifat multifaktorial, antara lain berhubungan dengan faktor genetik dan faktor lingkungan. ${ }^{3}$

\section{Penatalaksanaan}

Penatalaksanaan hanya dapat dilakukan melalui tindakan pembedahan (palatoplasty). Tujuan utama tindakan pembedahan tersebut ialah untuk mengembalikan keutuhan bentuk anatomi dan fungsi palatum ${ }^{4}$.

\section{METODE PENELITIAN}

Penelitian ini bersifat retrospektif deskriptif untuk mengetahui profil palatoskisis di Bagian Ilmu Bedah Plastik RSUP Prof. Dr. R.D. Kandou Manado periode JanuariDesember 2011.

Semua pasien dengan diagnosis palatoskisis dan labiopalatoskisis di Poliklinik Bedah BLU RSUP Prof. Dr. R.D. Kandou Manado periode Januari-Desember 2011 dimasukkan dalam penelitian dengan karakteristik sosiodemografi yaitu usia dan jenis kelamin serta karakteristik klinis yaitu jenis kelainan, etiologi, jenis kesumbingan, lokasi kesumbingan, jumlah operasi, dan jenis operasi. 


\section{HASIL PENELITIAN}

Berdasarkan data penelitian retrospektif deskriptif di Poliklinik Bedah BLU RSUP Prof. Dr. R.D. Kandou Manado periode Januari-Desember 2011, pasien yang terdiagnosis palatoskisis dan labiopalatoskisis berjumlah 40 orang, yang terdiri dari 22 kasus palatoskisis dan 18 kasus labiopalatoskisis.

\section{Karakteristik demografik menurut jenis kelamin}

Berdasarkan tabel distribusi menurut jenis kelamin, palatoskisis lebih sering ditemukan pada perempuan (53\%) (Tabel 1).

Tabel 1. Distribusi palatoskisis menurut jenis kelamin.

\begin{tabular}{lcc}
\hline Jenis kelamin & $\mathbf{N}$ & $\mathbf{\%}$ \\
\hline Laki-Laki & 19 & 47 \\
Perempuan & 21 & 53 \\
Total & 40 & 100 \\
\hline
\end{tabular}

\section{Karakteristik demografik menurut} kelompok usia yang dioperasi

Berdasarkan tabel distribusi menurut kelompok usia, palatoskisis terbanyak ditemukan pada usia 1-4 tahun (57\%) dan yang paling sedikit yaitu 10-14 tahun (8\%) (Tabel 2).

Tabel 2. Distribusi palatoskisis menurut usia.

\begin{tabular}{lcc}
\hline Usia & $\mathbf{N}$ & $\mathbf{\%}$ \\
\hline $1-4$ th & 23 & 57 \\
$5-9$ th & 9 & 22 \\
$10-14$ th & 3 & 8 \\
$>15$ th & 5 & 13 \\
Total & 40 & 100 \\
\hline
\end{tabular}

\section{Karakteristik klinis menurut jenis kelainan}

Berdasarkan tabel distribusi menurut jenis kelainan, palatoskisis $(55 \%)$ lebih banyak ditenukan daripada labiopalatoskisis (45\%) (Tabel 3).
Tabel 3. Distribusi palatoskisis menurut jenis kelainan.

\begin{tabular}{lcc}
\hline Jenis Kelainan & N & \% \\
\hline Palatoskisis & 22 & 55 \\
Labiopalatoskisis & 18 & 45 \\
Total & 40 & 100 \\
\hline
\end{tabular}

\section{Karakteristik klinis menurut jenis etiologi}

Berdasarkan tabel distribusi menurut etiologi, palatoskisis yang tersering diakibatkan oleh faktor lingkungan (58\%) (Tabel 4).

Tabel 4. Distribusi palatoskisis menurut etiologi.

\begin{tabular}{lcc}
\hline Etiologi & n & \% \\
\hline Genetik & 15 & 37 \\
Lingkungan & 23 & 58 \\
Unknown & 2 & 5 \\
Total & 40 & 100 \\
\hline
\end{tabular}

\section{Karakteristik klinis menurut jenis kesumbingan}

Berdasarkan tabel distribusi menurut jenis kesumbingan, yang paling banyak ialah kasus palatoskisis unilateral $(52,5 \%)$ (Tabel 5).

Tabel 5. Distribusi palatoskisis menurut jenis kesumbingan.

\begin{tabular}{lcc}
\hline Jenis kesumbingan & $\mathbf{N}$ & $\mathbf{\%}$ \\
\hline Palatoskisis unilateral & 21 & 52,5 \\
Palatoskisis bilateral & 1 & 2,5 \\
Labiopalatoskisis unilateral & 12 & 30 \\
Labiopalatoskisis bilateral & 6 & 15 \\
Total & 40 & 100 \\
\hline
\end{tabular}

\section{Karakteristik klinis menurut lokasi kesumbingan}

Berdasarkan tabel distribusi menurut lokasi kesumbingan, paling banyak ditemukan lokasi defek palatoskisis dengan data tak lengkap (47,5\%) (Tabel 6). 
Tabel 6. Distribusi palatoskisis menurut lokasi kesumbingan.

\begin{tabular}{lcc}
\hline Lokasi defek & N & \% \\
\hline Kanan & 6 & 15 \\
Kiri & 8 & 20 \\
Bilateral & 7 & 17.5 \\
Data tak lengkap & 19 & 47.5 \\
Total & 40 & 100 \\
\hline
\end{tabular}

\section{Karakteristik klinis menurut jumlah kasus palatoskisis yang dioperasi dan tidak dioperasi}

Berdasarkan tabel distribusi menurut jumlah yang dioperasi dan yang tidak dioperasi, paling banyak pasien palatoskisis yang dioperasi (95\%) dibandingkan dengan yang tidak dioperasi (5\%) (Tabel 7).

Tabel 7. Distribusi palatoskisis menurut jumlah pasien yang dioperasi dan tidak dioperasi.

\begin{tabular}{lll}
\hline Pasien & $\mathbf{N}$ & $\mathbf{\%}$ \\
\hline Dioperasi & 38 & 95 \\
Tidak dioperasi & 2 & 5 \\
Total & 40 & 100 \\
\hline
\end{tabular}

\section{Karakteristik klinis menurut jenis operasi}

Berdasarkan tabel distribusi menurut jenis operasi, yang paling banyak digunakan ialah palatoplasty $(72,5 \%)$ dibandingkan labiopalatoplasty (7,5\%) (Tabel 8).

Tabel 8. Distribusi palatoskisis menurut jenis operasi.

\begin{tabular}{lcc}
\hline Jenis operasi & $\mathbf{N}$ & $\mathbf{\%}$ \\
\hline Palatoplasty & 29 & 72,5 \\
Labioplasty & 8 & 20 \\
Labiopalatoplasty & 3 & 7,5 \\
Total & 40 & 100 \\
\hline
\end{tabular}

\section{BAHASAN}

Dari hasil penelitian jumlah kasus kesumbingan di Bagian Bedah Plastik
RSUP Prof. Dr. R.D. Kandou Manado periode Januari-Desember 2011 ditemukan 40 kasus dengan palatoskisis sebanyak $55 \%$ dan labiopalatoskisis sebanyak $45 \%$. Jenis kela-min perempuan lebih sering menderita kelainan ini (Tabel 2); hal ini sesuai dengan acuan pustaka yang menyebutkan bahwa insiden palatoskisis lebih tinggi pada perempuan dibandingkan laki-laki karena laki-laki memiliki vaskularisasi yang lebih baik sehingga pada laki-laki lebih cepat terjadi penutupan palatum. ${ }^{1}$

Tabel 3 memaparkan kelompok usia yang paling banyak ditangani yaitu 1-4 tahun, diikuti 5-9 tahun, >15 tahun, dan 1014 tahun. Usia yang paling banyak ditangani yaitu 1-4 tahun tidak sesuai dengan acuan pustaka yang menyatakan tindakan operasi biasanya dilakukan pada usia 5 tahun untuk mengantisipasi terjadinya gangguan pertumbuhan wajah. Acuan pustaka lain menyatakan tindakan operasi langit-langit tahap I (dini dan usia 1 tahun) untuk menutup palatum molle (furlow veloplasty) dan kemudian operasi langitlangit tahap II ditunda sampai pasien berumur 5 tahun. ${ }^{1}$

Tabel 4 memperlihatkan penyebab palatoskisis tersering ialah faktor lingkungan (58\%). Hal ini disebabkan karena kurangnya perhatian dari para ibu hamil dalam mengonsumsi obat-obatan. Selain itu, umumnya pasien palatoskisis berasal dari sosioekonomi rendah dan berpendidikan menengah kebawah sehingga perlu dilakukan penyuluhan mengenai palatoskisis oleh para medis.

Tabel 5 menunjukkan jenis kesumbingan, palatoskisis unilateral $(52,5 \%)$ jauh lebih banyak dibandingkan yang bilateral $(2,5 \%)$. Lokasi defek dengan data tak lengkap sebanyak 47,5\% menyebabkan data yang didapatkan tidak valid, namun lokasi defek yang paling sering yaitu pada sisi kiri. Hal ini sesuai dengan acuan pustaka yang menyebutkan bahwa pada sisi kiri lebih sering ditemukan defek karena sisi kanan memiliki vaskularisasi yang lebih baik sehingga langit-langitnya lebih dahulu mencapai bagian medial. ${ }^{1}$ 
Tabel 7 memperlihatkan bahwa kasus palatoskisis yang dioperasi jauh lebih banyak (95\%) dibandingkan dengan yang tidak dioperasi $(5 \%)$ sehingga penanganan dapat dikatakan cukup baik. Alasan pasien yang tidak dioperasi yaitu karena usia yang masih sangat muda (9 hari) sehingga tindak-an operasinya ditunda.

Tabel 8 menunjukkan bahwa jenis operasi di Bagian Bedah Plastik RSUP Prof. Dr. R.D. Kandou Manado periode Januari-Desember 2011 yang paling sering dilakukan ialah palatoplasty untuk memperbaiki keadaan anatomis dari palatum.

\section{SIMPULAN}

Dari hasil penelitian dapat disimpulkan bahwa di Bagian Ilmu Bedah Plastik RSUP Prof. Dr. R.D. Kandou Manado selama periode Januari-Desember 2011 sebagian besar kasus palatoskisis dan labiopalato-skisis ditemukan unilateral dengan lokasi defek terbanyak di bagian kiri. Jenis kelamin perempuan lebih sering ditemukan dan etiologi tersering yaitu faktor lingkungan. Kelompok usia yang tersering ditangani yaitu 1-4 tahun dan tindakan operasi yang tersering digunakan ialah palatoplasty.

\section{DAFTAR PUSTAKA}

1. Oldham, Keith T, Colombani, Paul M, Foglia, Robert P, Skinner, Michael A. Principles and Practice of Pediatric Surgery (Fourth Edition). Pennsylvania: Lippincott Williams \& Wilkins, 2005; p.54.

2. Bibir sumbing [homepage on the Internet]. Nodate [cited 2011 Sep 12]. Available from: http://www.scribd.com/doc/101 501011/BIBIR-SUMBING.

3. Koran Indonesia Sehat. Penanganan celah bibir dan celah langit-langit. [homepage on the Internet]. 2000 [update 2009 Des; Cited 2011 Sep 12]. Available from: http://koranindonesiasehat.word press.com/2009/12/02/bibir-sumbingpenanganan-celah-bibir-cleft-lips-bibirsumbing-cheiloschisis-dan-celah-langitlangit-cleft-palatepalatoschisis/).

4. Wibowo D. Anatomi Tubuh Manusia. Jakarta: PT. Gramedia Pustaka Utama; 2009. 